\title{
Channel-specific input/output transformations arising from the interaction between dynamic synapses and subthreshold oscillations
}

\author{
Roberto Latorre ${ }^{1}$, Joaquin J Torres ${ }^{2}$, Pablo Varona ${ }^{1 *}$ \\ From 24th Annual Computational Neuroscience Meeting: CNS*2015 \\ Prague, Czech Republic. 18-23 July 2015
}

Subthreshold oscillations are observed in a wide variety of neurons in the nervous system (e.g. see $[1,2])$. They typically appear associated to resonance phenomena that allow, for instance, the implementation of intrinsic memory mechanisms for the detection of specific spike sequences in single neurons and neural networks [3-5]. On the other hand, synaptic transmission and, therefore, the corresponding input/output transformation in the postsynaptic cell are affected by recent presynaptic activity. Dynamic synapses modulate incoming information increasing (facilitation) or decreasing (depression) the postsynaptic response. This modulation provides additional characteristic time scales to the single neuron and network processing [6,7]. In the context of a neuron displaying subthreshold oscillations, the interplay between these additional time scales and the characteristic intrinsic fast and slow dynamics underlying the neuron's oscillatory activity can significantly affect its input/output transformation.

Neuronal intrinsic subthreshold oscillations and dynamic synapses underlie several computational properties both at the single neuron and the network levels. Traditionally, intrinsic oscillations and dynamic synapses have been studied separately and their interaction has attracted almost no attention. In this work, we use a conductance-based neuron model and a dynamic synapse to investigate how intrinsic subthreshold oscillations and the short-term plasticity of a depressing synapse act together to shape its resonant properties and the corresponding input/output transformation. Our results suggest that factors such as the maximum hyperpolarization

\footnotetext{
* Correspondence: pablo.varona@uam.es

'Dpto. de Ingeniería Informática, Escuela Politécnica Superior, Universidad Autónoma de Madrid, 28049 Madrid, Spain

Full list of author information is available at the end of the article
}

level, the oscillation amplitude and frequency or the resulting firing threshold can be modulated by synaptic depression. This shapes the postsynaptic neuron's resonant properties arising from the subthreshold oscillation and leads to complex channel-specific input/output relations. Thus, a low-cost modification in synaptic parameters can produce a significant different response. This complex synaptic-dependent input/output transformation allows the implementation of cost-effective information discrimination mechanisms in single neurons by just tuning the depression level of the synaptic channel without modifying the intrinsic neural dynamics.

\section{Acknowledgements}

Authors acknowledge support by MINECO TIN2012-30883 and FIS201343201-P.

\section{Authors' details}

${ }^{1}$ Dpto. de Ingeniería Informática, Escuela Politécnica Superior, Universidad Autónoma de Madrid, 28049 Madrid, Spain. ${ }^{2}$ Dpto. de Electromagnetismo y Física de la Materia, and Institute Carlos I for Theoretical and Computational Physics, University of Granada, Granada, Spain.

\section{Published: 18 December 2015}

\section{References}

1. Llinás R, Yarom Y: Oscillatory properties of guinea-pig inferior olivary neurones and their pharmacological modulation: an in vitro study. J Physiol 1986, 376:163-182.

2. Giocomo LM, Zilli EA, Fransén E, Hasselmo ME: Temporal Frequency of Subthreshold Oscillations Scales with Entorhinal Grid Cell Field Spacing. Science (80- ) 2007, 315:1719-1722.

3. Baroni F, Varona P: Subthreshold oscillations and neuronal input-output relationships. Neurocomputing 2007, 70:1611-1614.

4. Baroni F, Torres JJ, Varona P: History-dependent excitability as a singlecell substrate of transient memory for information discrimination. PLOS One 2010, 5:e15023.

5. Latorre R, Aguirre C, Rabinovich Ml, Varona P: Transient dynamics and rhythm coordination of inferior olive spatio-temporal patterns. Front Neural Circuits 2013, 7:138. 
6. Klug A, Borst JGG, Carlson BA, Kopp-Scheinpflug C, Klyachko VA, Xu-Friedman MA: How Do Short-Term Changes at Synapses Fine-Tune Information Processing? J Neurosci 2012, 32:14058-14063.

7. Torres $\mathrm{JJ}$, Kappen $\mathrm{HJ}$ : Emerging phenomena in neural networks with dynamic synapses and their computational implications. Front Comp Neurosci 2013, 7.

doi:10.1186/1471-2202-16-S1-P274

Cite this article as: Latorre et al:: Channel-specific input/output

transformations arising from the interaction between dynamic synapses and subthreshold oscillations. BMC Neuroscience 2015 16(Suppl 1):P274.

Submit your next manuscript to BioMed Central and take full advantage of:

- Convenient online submission

- Thorough peer review

- No space constraints or color figure charges

- Immediate publication on acceptance

- Inclusion in PubMed, CAS, Scopus and Google Scholar

- Research which is freely available for redistribution

Submit your manuscript at www.biomedcentral.com/submit
C Biomed Central 